\title{
ANALISIS BISNIS DALAM PERENCANAAN STRATEGIS SISTEM INFORMASI PADA PD. INDRASARI
}

\author{
Sumardiono \\ Program Studi Manajemen Informatika, AMIK Purnama Niaga, Indramayu, Indonesia \\ Jl. Ir. H. Djuanda No. 256A Kelurahan Karanganyar, Kabupaten Indramayu \\ Telp. (0234) 274464 \\ Email: dyons.2015@gmail.com
}

\begin{abstract}
The development of modern trade is strongly influenced by advances and conveniences in information systems. Business and marketing services are supportive of accessing the digital world, which we usually know as e-shop or e-commerce. E-commerce is virtual in the sense that it exists on the Internet, and physical existence outside the Internet is limited (Azam 2012)[1]. PD. Indrasari is a home-based business or IKM whose scope of business is still conventional, meaning that business and business applications are still manual without the interference of information technology.

Research in PD. Indrasari is only in its external business environment, so researchers use the method described by Ward and Peppard to obtain a business strategy. The methods are PEST analysis, PEST analysis (political, economic, social and technological)[2] and Five Porter Forces analysis The Porter's Five Forces Model includes Bargaining power of suppliers, bargaining power of buyers, threat of new entrants, and threat of substitutes [3]. With this PEST analysis to determine the condition of governance / regulation, economy, social and technology in the area of research object and the Five Porter Forces analysis to determine competition in terms of production and marketing needs. By knowing some of the results of the analysis, it will be formulated as a component in the planning of an information system strategy, in order to obtain recommendations for information systems and applications that will be implemented based on the planned time.
\end{abstract}

Keywords - home industry, IKM, PEST, Five Porter Forces

\begin{abstract}
ABSTRAK
Perkembangan perdangangan modern sangat dipengaruhi dengan kemajuan dan kemudahan dalam sistem informasi. Pelayanan bisnis dan pemasaran sangatlah menunjang dalam pengaksesan dunia digital yang biasa kita kenal dengan sebutan $e$-shop atau $e$ commerce. E-commerce is virtual in the sense that it exists on the Internet, and physical existence outside the Internet is limited (Azam 2012)[1]. PD. Indrasari merupakan salah satu usaha rumahan atau IKM yang lingkup bisnisnya masih dikatakan konvesional, artinya penerapan usaha dan bisnis masih manual tanpa adanya campur tangan teknologi informasi. Penelitian di PD. Indrasari hanya pada lingkungan bisnis eksternalnya, sehingga peneliti menggunakan metode sebagaimana dijelaskan oleh Ward and Peppard untuk memperoleh strategi bisnis. Adapun metode tersebut adalah analisis PEST, PEST (political, economic, social and technological)[2] dan analisis Five Porter Forces, The Porter's Five Forces Model includes Bargaining power of suppliers, bargaining power of buyers, threat of new entrants, and threat of substitutes [3].
\end{abstract}


Dengan analisis PEST ini untuk mengetahui kondisi kepemerintahan/ regulasi, ekonomi, sosial dan teknologi di wilayah obyek penelitian dan analisis Five Porter Forces untuk mengetahui persaingan dalam hal kebutuhan produksi dan pemasaran. Dengan mengetahui beberapa hasil analisa, maka akan dirumuskan sebagai komponen dalam perencanaan strategi sistem informasi, sehingga memperoleh rekomendasi sistem informasi dan aplikasi yang akan diterapkan berdasarkan waktu yang direncanakan.

\section{Kata kunci- home industry, IKM, PEST, Five Porter Forces}

\section{Pendahuluan}

Perdagangan merupakan suatu komoditas yang sangat menguntungkan bagi para pengusaha dan investor [4], sehingga dibutuhkannya suatu rumusan bahkan arah dari suatu perdagangan yang kekinia. Sifat modernisasi selalu diiringi dengan teknologi yang teruji akan keamanan dan manfaat yang lebih, sehingga memberikan keuntungan bagi beberapa pihak, tidak terkecuali dari sektor perdagangan. Sektor perdagangan secara konvesional sering terkendal, baik letak geografis ataupun kendala lain. Akan tetapi, dengan e-niaga tidak ada kendala geografis dalam memasarkan karena dukungan dari Internet, (Azam 2012) [1].

Perdagangan yang melibatkan beberapa kelompok usaha yang biasanya dilakukan oleh orang-orang di lingkungannya sehingga memberikan nilai ekonomis, disebut home industry [5]. Home industri adalah sistem produksi yang menghasilkan nilai tambah yang dilakukan di lokasi rumah perorangan, dan bukan di suatu pabrik [6]. Biasanya home industri bermula dari keluarga yang memiliki kreativitas dalam memperoleh nilai ekonomis sehingga memberikan dampak terhadap lingkungan sekitar rumahnya.
Tumbuh kembangnya industri rumahan atau bisa disebut industri kecil dan menengah (IKM) dari tahun ke tahun, sehingga diharapkan oleh pemerintah dapat tumbuh lebih di tahun 2019 hingga mencapai 5000 IKM [7].

Perindustrian di Kabupaten Indramayu yang bergerak dalam industri kecil dan menengah (IKM) masih tergolong kecil dari jumlah pertumbuhannya karena masyarakat Indramayu masih awam dalam menggerakan ekonomi kreatif. Di tahun 1970-an, tepatnya di desa Kenanga Kecamatan Sindang Kabupaten Indramayu awal industri rumahan dengan hasil olahannya berupa kerupuk. Home industri ini dilakukan oleh salah seorang mantan pekerja dari sodagar dari China yaitu H. Saein. Bermula dari rumah ke rumah, sehingga berkembang menjadi industri yang menengah dengan memperoleh keuntungan lebih dari 500 juta/ tahun. Hanya dalam memasarkan produknya masih bersifat konfensional, tanpa adanya campur tangan teknologi dan sistem informasi. Oleh sebab itu, perlunya dukungan teknologi informasi dan sistem informasi dalam menjalankan manajemen pemasaran, sehingga masyarakat sebagai konsumen dapat mengerti tantang kerupuk udang dan ikan produksi dari PD. Indrasari. 


\section{Metode Penelitian}

Penelitian ini menggunakan Model Strategi SI/ TI pada lingkup lingkungan bisnis eksternal dengan menggunakan metode PEST Analysis dan Porter Five Forces Analysis sebagaimana dijelaskan oleh John Ward \& Joe Peppard.

The IS strategy defines the organization's requirement or 'demand' for information and systems to support the overall strategy of the business.It is firmly grounded in the business, taking into consideration both the competitive impact and alignment requirements of IS/IT [8]

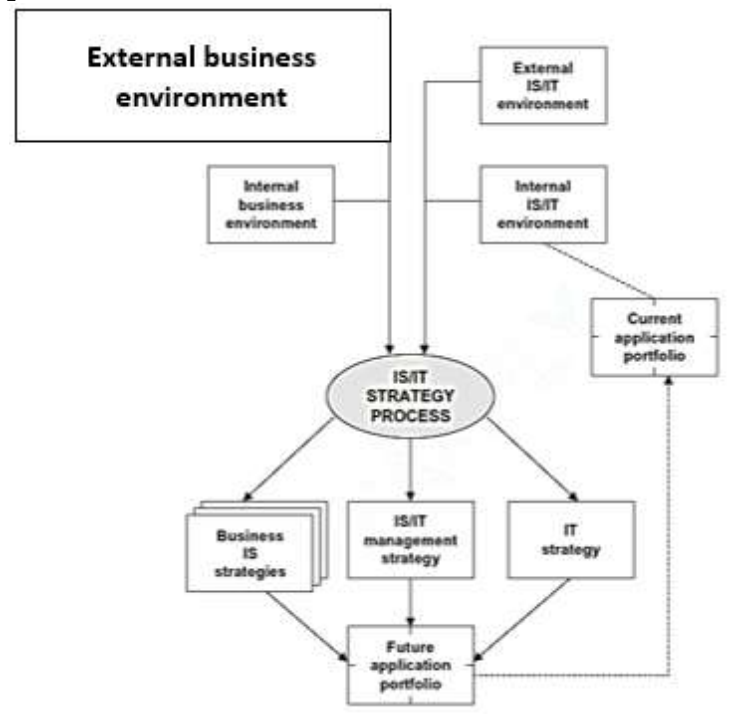

Gambar 1. IS/IT Strategic Model[8]

Di dalam IS/IT Strategic Model

(Gambar 1) dengan lingkungan bisnis eksternal dan metode yang digunakan penelitian ini adalah analisis PEST dan analisis Porter Five Forces, yang tujuan adalah memperoleh konsep strategi bisnis (Gambar 2. Alur Penelitian).

\section{a. Alur Penelitian}

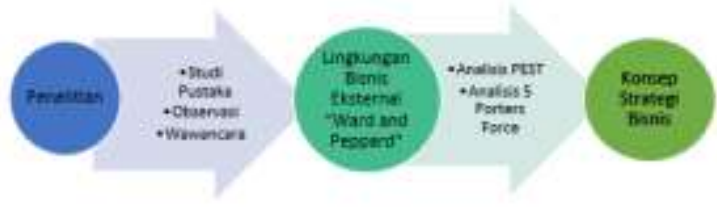

Gambar 2. Alur Penelitian

Sebagaimana telah dijelaskan di atas, bahwa penelitian ini hanya mencakup eksternal bisnis di PD. Indrasari dengan analisis PEST dan analisis Porter Five Forces sebagai metodenya.

\section{Analisis PEST}

The present complex world require as far as is feasible, it consider impact of important factors related to organizations in strategic planning. In strategic planning, it can use different analytical methods and techniques that one of them is PEST analysis [9]. PEST is a useful strategic method for understanding market growth or decline, business position, potential and direction in an organisation (The Times 2009)[2].

\section{Analisis Porter Five Force}

These forces are the threat of new entrants, the threat of substitution, the bargaining power of buyers, the bargaining power of suppliers, and the rivalry amongst existing competition in the industry [10]. Porter's framework applies a rigorous, validated structure to understand industry competition through the following five forces: rivalry among existing competitors, the threat of new entrants, the power of buyers, the power of suppliers, and the threat of substitutes [11]. 
The state of competition in an industry depends on five basic forces [12].

b. Proses Bisnis

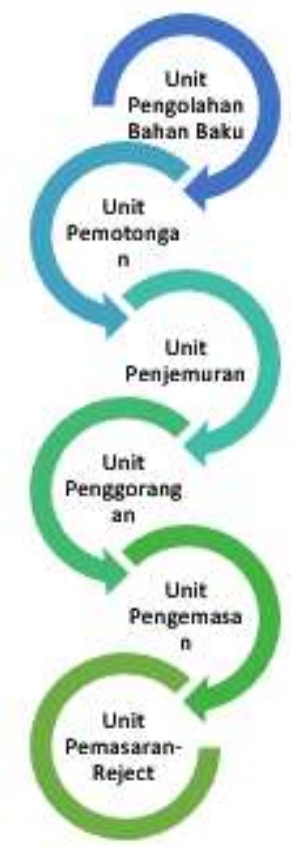

Gambar 3. Proses Bisnis PD. Indrasari

\section{HASIL DAN PEMBahasan}

Penelitian ini merupakan penelitian deskriptif - kualitatif, serta peneliti menggunakan metode PEST dan Five Porter Force berdasarkan model John Ward and Joe Peppard yang mendeskripsikan lingkungan bisnis eksternalnya, sehingga bisa menjawab tantangan keunggulan kompetitif bisnis. Data sekunder yang diperoleh, adalah sebagai berikut :

1) Dukungan dari Pemerintah sangat dibutuhkan, terutama dalam pemberian modal;

2) Tidak adanya investor baik pemerintah daerah ataupun investor swasta;
3) Kerjasama antar pelaku usaha (lokal) masih dilakukan dengan sangat baik, bukti dari anggota APKI;

4) Sumberdaya Manusia yang masih terbilang sedikit mengenal dunia digital

5) Buruh adalah masyarakat sekitar kawasan pabrik;

6) Tidak adanya regulasi dari pemerintah dalam kesejahteraan buruh/ karyawan;

7) Kurangnya pelatihan/ workshop bagi para pelaku usaha (IKM);

8) Kurangnya pengetahuan teknologi informasi dan sistem informasi dalam manajemen pemasaran.

Dari beberapa data di atas, disimpulkan dengan menggunakan metode PEST dan

\section{Five Porter Forces}

\section{Analisis PEST}

Tabel 1. PEST

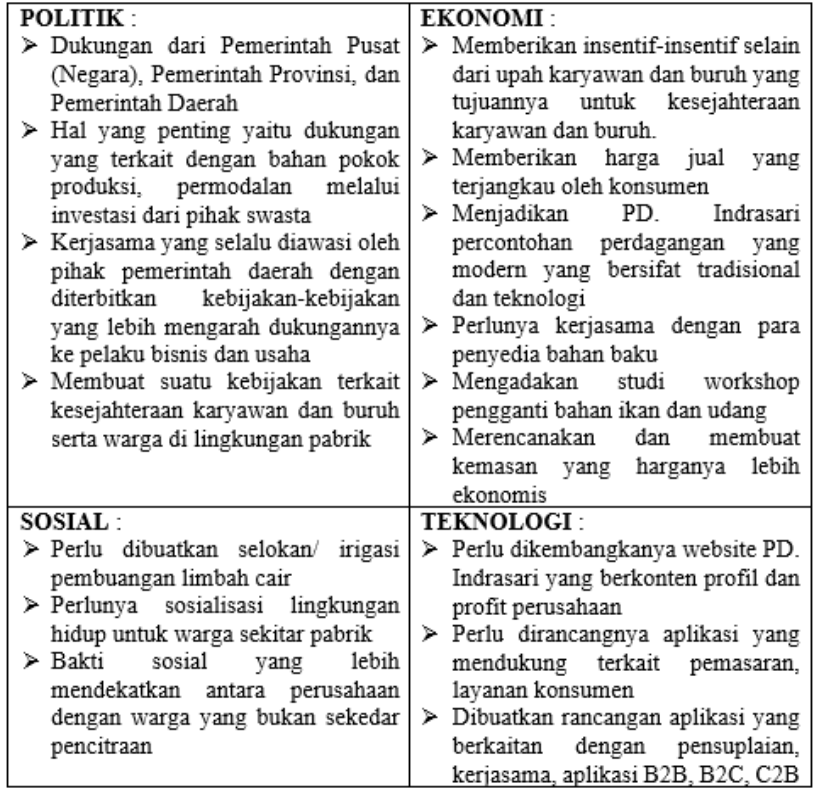




\section{Analisis Porter Five Forces}

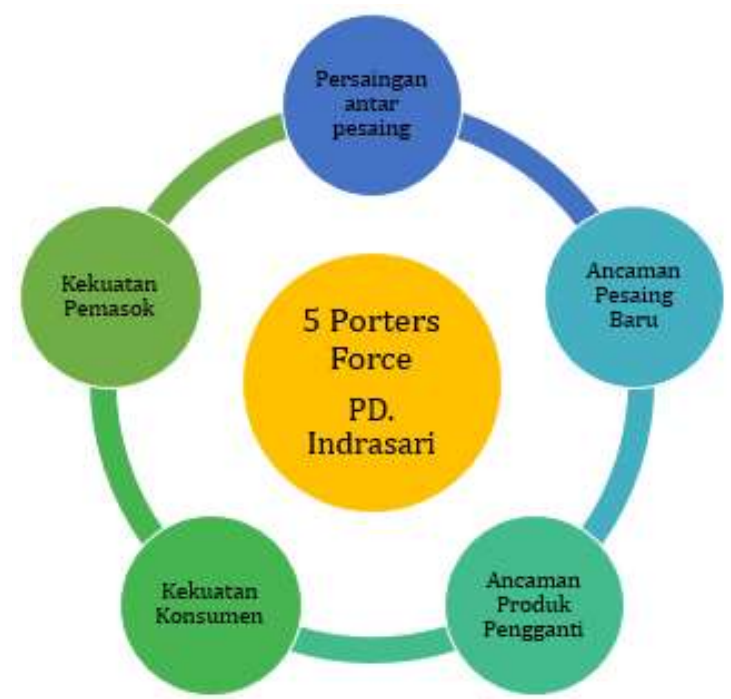

Konsep diperoleh dari analisis tersebut adalah sebagai berikut :

a. Persaingan antar pesaing (Rivalry among existing competitors)

Persaingan dengan IKM sejenis dalam tingkat daerah masih terbilang kecil, akan tetapi untuk tingkat nasional terbilang menengah pesaing, karena bisnis kerupuk udang atau ikan merupakan bisnis industri kecil. Adanya pernyataan tersebut sebaiknya IKM tersebut untuk meningkatkan promosi produk.

b. Ancaman Pesaing Baru (Threat of New Entrants)

Kelompok pengolah yang baru (pesaing) terkandang tidak dapat melanjutkan dikarenakan stok bahan baku yang sulit karena manggunakan ikan jenis tertentu, sehingga pabrik ataupun kelompok pengolah tersebut akan mengalami gulung tikar dalam jangka waktu 6 bulan s.d. 12 bulan. Disimpulkan bahwa perlunya manajemen pengelolaan terpadu pada IKM tersebut, sehingga apabila ada permasalahan di tiap bagian/unit akan segera ditangani.

c. Ancaman Produk Pengganti (Threat of substitute products or services)

Munculnya pabrik/ organisasi yang terlibat dalam perdagangan keripik kulit ikan merupakan produk pengganti dari kerupuk, akan tetapi produk tersebut mengalami kesulitan dalam bahan bakunya (kulit ikan). Sehingga kemungkinan kecil adanya produk pengganti. Sebaiknya IKM lebih diarahkan ke kreativitas dan inovasi bentuk produk, sehingga ancaman bentuk dan rasa bias menjadi sasaran.

d. Kekuatan Konsumen/ Pengguna (Bargaining Power of Buyers)

Seiring dengan berkembangnya pedagang keripik kulit ikan yang dikonsumsi sehari - hari sebagai teman hidangan makanan dan bertambahnya pabrik keripik kulit ikan, maka efek konsumen/ pembeli berkurang untuk kerupuk udang dan ikan, akan tetapi tidak begitu signifikan. Bahwa ini bisa ditangani dengan menerapkan strategi promosi, 
harga, dan antar barang kepada konsumen tunggal atau toko.

e. Kekuatan Pemasok/ Investasi (Bargaining Power of Suppliers)

Dengan banyaknya pemasok (nelayan tambak/ nelayan laut) yang memiliki nilai tawar yang kuat bagi perusahaan/ IKM. Jika pemasok tersebut memberikan/ memasok ke perusahaan selain IKM dengan harga yang relatif murah, dapat memberikan kesulitan bagi IKM untuk menentukan harga yang barsaing. Pernyataan di atas dapat disimpulkan bahwa perlu adanya bantuan dari pihak pemerintah terutama terkait harga kebutuhan bahan baku.

\section{SIMPULAN}

Untuk menyusun konsep strategi bisnis pada PD. Indrasari desa Kenanga Kabupaten Indramayu, dengan menggunakan pendekatan John Ward and Joe Peppard yaitu dengan menganalisis lingkungan bisnis eksternal pada lingkungan Politik, Ekonomi, Sosial, dan Teknologi serta menganalisis 5 Porter Forces, yaitu persaingan antar pesaing, ancaman pesaing baru, ancaman produk pengganti, kekuatan konsumen, dan kekuatan pemasok. Adapun tahapan tahapan untuk memperoleh analisis lingkungan bisnis eksternalnya yaitu :
Tahap Pertama : menentukan dan mengolah data analisis PEST, yaitu dengan memperoleh deskripsi berupa dukungan dan pengawasan pemerintah pusat, pemerintah provinsi, dan pemerintah daerah serta adanya kebijakankebijakan (regulasi) yang mendorong produktivitas perusahaan.

Tahap Kedua : menentukan dan mengolah data analisis Five Porter Forces, seperti persaingan antar pesaing masih terbilang kecil karena jumlah perusahaan kerupuk di Kabupaten Indramayu masih sedikit, ditahun 2018 kurang dari 40 IKM; untuk ancaman pesaing baru masihlah kurang karena IKM ini masih bersifat konvensional baik produksi ataupun teknologi informasi; dilihat dari ancaman produk pengganti bahwa dari pemaparan para responden masih kemungkinan kecil, karena bahan baku yang kurang; kekuatan konsumen dibuktikan bahwa karakteristik rasa yang beda dengan keripik kulit ikan, sehingga konsumen enggan berpindah; Kabupaten Indramayu merupakan daerah strategis pemasok udang dan ikan dan disebut sebagai ketahanan pangan, itu merupakan kekuatan pemasok walau tergantung dengan keadaan alam.

Dari beberapa hasil analisis di atas, maka disimpulkan konsep strategi bisnis pada PD. Indrasari perlu dukungan politik, 
dukungan ekonomi, dukungan sosial, dukungan teknologi, dukungan saranaprasarana, dukungan konsumen, dukungan distributor, dukungan suplyer, dan dukungan sumberdaya manusia yang unggul.

\section{PENELITIAN LANJUTAN}

Penelitian ini hanya memberikan suatu konsep strategi bisnis dan masih perlu penelitian lebih lanjut terutama dalam lingkungan eksternal SI/TI, dengan capaian strategi SI/TI, capaian berikutnya adalah blueprint pengembangan SI/TI di PD. Indrasari.

\section{UCAPAN TERIMA KASIH}

Penulis mengucapkan terima kasih kepada Direktur AMIK Purnama Niaga dan jajarannya sebagai lembaga yang mendukung kegiatan penelitian baik financial maupun fasilitas lainnya, Ketua APKI (Asosiasi Pengusaha Kerupuk Indramayu), Supendi, SH, MH yang telah memberi motivasi, serta kepada H. Saein seorang motivator tumbuhnya IKM kerupuk udang desa Kenanga, Kecamatan Sindang, Kab. Indramayu.

\section{DAFTAR PUSTAKA}

B. T. Ward, J. C. Sipior, and L. Volonino, "Internet Jurisdiction for E-commerce," J. Internet Commer. vol. 15 , no. 1 , pp. $1-17,2016$, doi:
10.1080/15332861.2015.1109988.

[2] L. Zhu, E. Hiltunen, E. Antila, F. Huang, and L. Song, "Investigation of China's bio-energy industry development modes based on a SWOT-PEST model," Int. J. Sustain. Energy, vol. 34, no. 8, pp. $552-559$, 2015 , doi: 10.1080/14786451.2014.884096.

[3] I. Gamayanto, "Porter S Five Forces Model Scott Morton S Five Forces Model Bakos Treacy Model Analyzes Strategic Information Systems Management," J. Inform., vol. 5, no. 2, pp. 134-134, 2004, doi:

10.9744/informatika.5.2.pp.127134.

[4] M. D. P. Saad and H. Siagian, "Sentimen Investor, Kendala Keuangan, dan Equity Market Timing," Financ. Bank., vol. 13, no. 1, pp. 1-15, 2011.

[5] Saifuddin Zuhri, "Analisis Pengembangan Usaha Kecil home Industri Sangkar Ayam Dalam Rangka Pengentasan Kemiskinan,” Manaj. dan Akunt., vol. 2, no. 3, pp. 46-65, 2013, [Online]. Available: https://media.neliti.com/media/publi cations/111956-ID-none.pdf.

[6] Riski Ananda, "JOM FISIP Vol. 3 No. 2 - Oktober 2016 Page 1," J. 
Ilmu Komun., vol. 3, no. 2, pp. 115, 2016.

[7] https://kemenperin.go.id/artikel/18855, "Jumlah-Unit-Usaha-dan-Tenaga-

Kerja-IKM-Ditargetkan-Naik-

Setiap-Tahun diakses pada tanggal 14 Mei 2020.”.

[8] J. Ward and J. O. E. Peppard, Strategic Planning for Information Systems Third Edition. John Wiley \& Sons, LTD, 2002.

[9] A. Gupta, "Environmental and pest analysis: An approach to external business environment," Int. J. Mod. Soc. Sci., vol. 1, no. 2, pp. 34-43, 2013.

[10] M. Mittal, "Competitive Analysis of Nissan Motors Pvt Ltd . Beyond Porter ' s 5 Force Model," Int. J. Commer. Bus. Manag., vol. 6, no. 3, pp. 1-10, 2017.

[11] N. N. O’Hara, L. E. Nophale, L. M. O’Hara, C. A. Marra, and J. M. Spiegel, "Tuberculosis testing for healthcare workers in South Africa: A health service analysis using Porter's Five Forces Framework," Int. J. Healthc. Manag., vol. 10, no. 1, pp. 49-56, 2017, doi: 10.1080/20479700.2016.1268814.

[12] M. Porter, "How Competitive Forces Shape Strategy,' Harvard Business Review.," J. Inf. Syst.
Manag., vol. 5, no. January, pp. 8587,1988

[13] Yulmaini, Y., Fitria, F., Purba, E., \& Murhadi, M. (2018, January). Perancangan Sistem Penjamin Mutu Dengan Model Capaian Mutu Berkelanjutan Di Perguruan Tinggi. In Seminar Nasional Teknologi Terapan (SNTT) (Vol. 5, pp. 220224).

[14] Aziz, R. A., Maria, D., Laila, S. N., \& Azima, M. F. (2020, April). Development of Knowledge Management System for Determining Organizational Performances, Total Quality Management, And Culture. In Journal of Physics: Conference Series (Vol. 1529, No. 2, p. 022063). IOP Publishing. 